Terr. Atmos. Ocean. Sci., Vol. 18, No. 3, 567-576, August 2007

\title{
Effect of Finite Frequency Bandwidth Limitation on Evaluations of Seismic Radiation Energy of the 1999 Chi-Chi Earthquake
}

\author{
Jeen-Hwa Wang ${ }^{1, *}$ and Ming-Wey Huang ${ }^{2,3}$
}

(Manuscript received 23 June 2006, in final form 15 January 2007)

\begin{abstract}
Based on the $\omega^{-2}$ and $\omega^{-3}$ source models, we explore the effect on estimates of seismic radiation energy, $E_{s}$, caused by finite frequency bandwidth limitation of source spectra. Let $f_{c}$ be the corner frequency of a source spectrum and $f_{u}$ and $f_{c}$ are, respectively, the upper and lower bounds of a frequency band in use. Results show that the effect depends on $f_{u} / f_{c}$ and $f_{l} / f_{c}$, and $E_{s}$ is under-estimated when $f_{1}>0$ and $f_{u}<\infty$. When $f_{u} / f_{c}<20$, the effect is sensitive to both $\mathbf{f}_{\mathrm{l}} / \mathbf{f}_{\mathrm{c}}$ and $\mathbf{f}_{\mathrm{u}} / \mathbf{f}_{\mathrm{c}}$ for the $\omega^{-2}$ source model, but mainly to $\mathbf{f}_{\mathrm{l}} / \mathbf{f}_{\mathrm{c}}$ for the $\omega^{-3}$ model. When $f_{u} / f_{c}>20$, the effect is insensitive only to $f_{u} / f_{c}$ for the two models. Let $\mathrm{E}_{\mathrm{s}}$ ' be the seismic radiation energy estimated without removal of finite frequency bandwidth limitation. Results show: (1) $\mathbf{E}_{\mathrm{s}}{ }^{\prime} / \mathbf{E}_{\mathrm{s}}$ first slightly increases and then decreases with increasing $f_{c}$; or (2) $E_{s}{ }_{s}^{\prime} / E_{s}$ monotonously decrease with increasing $f_{c}$. For the $1999 \mathrm{M}_{\mathrm{s}} 7.6 \mathrm{Chi}-\mathrm{Chi}$ earthquake, Taiwan, $E_{s}$ was under-estimated by Hwang et al. (2001), and the degree of under-estimates varies from station to station.
\end{abstract}

(Key words: Seismic radiation energy, Corner frequency, Finite frequency bandwidth limitation)

\section{INTRODUCTION}

Seismic radiation energy, $\mathrm{E}_{\mathrm{s}}$, is an important parameter quantifying an earthquake (cf. Wang 2006). However, estimates of $E_{s}$ can be influenced by the source spectrum, seismic

\footnotetext{
1 Institute of Earth Sciences, Academia Sinica, Taipei, Taiwan, ROC

2 Institute of Geophysics, National Central University, Chung-Li, Taiwan, ROC

${ }^{3}$ National Science and Technology Center for Disaster Reduction, Taipei, Taiwan, ROC

* Corresponding author address: Dr. Jeen-Hwa Wang, Institute of Earth Sciences, Academia Sinica, Taipei, Taiwan, ROC; E-mail: jhwang@earth.sinica.edu.tw
} doi: 10.3319/TAO.2007.18.3.567(T) 
radiation patterns, seismic-wave attenuation, surface amplification, site effect, instrumental response, and noise. A correct evaluation of $\mathrm{E}_{\mathrm{s}}$ will help seismologists to understand source behavior more exactly. Boore (1988), Di Bona and Rovelli (1988), and Singh and Ordaz (1994) stressed that $E_{s}$ is underestimated when high-frequency signals are not included. Thus, the $E_{s}$ measured from local seismograms is usually larger than that done from teleseismic data (Bolt 1986; Smith et al. 1991; Singh and Ordaz 1994; Hwang et al. 2001; Huang et al. 2002). In principle, $E_{s}$ is measured for $\mathrm{f}=0-\infty \mathrm{Hz}$, while in practice the measurement can be made only for $\mathrm{f}_{1} \leqq \mathrm{f} \leqq \mathrm{f}_{\mathrm{u}}$ due to limitation in instrumental response and noise. This results in so-called finite frequency bandwidth limitation (denoted $f f b l$ hereafter). Ide and Beroza (2001) theoretically studied such an effect in a high-frequency regime. Based on the $\omega^{-2}$ source model, Wang (2004) studied the effect in both low- and high-frequency regimes. Both studies show underestimation of $\mathrm{E}_{\mathrm{s}}$ due to the $f f b l$-effect.

For the $1999 \mathrm{M}_{\mathrm{s}}$ 7.6 Chi-Chi earthquake, Wang (2004) made corrections only based on the $\omega^{-2}$ source model. However, Huang and Wang (2002) stressed that a $\omega^{-3}$ model must be taken into account for the northern fault plane of the earthquake. In this work, the ffbl-effects of source spectrum for both high- and low-frequency regimes on estimates of $\mathrm{E}_{\mathrm{s}}$ based on the $\omega^{-2}$ and $\omega^{-3}$ source models (Aki 1967; Brune 1970) will be discussed in detail. Theoretical results will be applied to correct estimates of the seismic radiation energy of the Chi-Chi earthquake.

\section{DEFINITION AND METHODOLOGY FOR MEASURING $E_{s}$}

The source spectra of earthquakes are mainly controlled by the low-frequency spectral level $\left(\Omega_{\mathrm{o}}\right)$ and corner frequency $\left(\mathrm{f}_{\mathrm{c}}\right)$ (Aki 1967). Theory and observations show that when $\mathrm{f}>\mathrm{f}_{\mathrm{c}}$, the spectral amplitude decays in a power-law function like $\mathrm{f}^{-\alpha}$. Commonly accepted powerlaw functions have either $\mathrm{f}^{-2}$ or $\mathrm{f}^{-3}$, which are, respectively, referred to as the $\omega^{-2}$ and $\omega^{-3}$ source models, where $\omega=2 \pi$ f (Aki 1967; Brune 1970).

Let $d(t)$ and $v(t)$ be the source displacement and velocity, respectively. Their Fourier transforms are, respectively, $D(f)$ and $V(f)$. $D(f)$ can be approximated by $D_{2}(f)=\Omega_{o} /\left[1+\left(f / f_{c}\right)^{2}\right]$ for the $\omega^{-2}$ model and $D_{3}(f)=\Omega_{\mathrm{o}} /\left[1+\left(\mathrm{f} / \mathrm{f}_{\mathrm{c}}\right)^{2}\right]^{3 / 2}$ for the $\omega^{-3}$ one (cf. Beresnev and Atkinson 1997). Hence, the approximations of $\mathrm{V}(\mathrm{f})$ are, respectively:

$$
\begin{aligned}
& \mathrm{V}_{2}(\mathrm{f})=2 \pi \mathrm{f} \Omega_{\mathrm{o}} /\left[1+\left(\mathrm{f} / \mathrm{f}_{\mathrm{c}}\right)^{2}\right], \\
& \mathrm{V}_{3}(\mathrm{f})=2 \pi \mathrm{f} \Omega_{\mathrm{o}} /\left[1+\left(\mathrm{f} / \mathrm{f}_{\mathrm{c}}\right)^{2}\right]^{3 / 2} .
\end{aligned}
$$

As $\mathrm{f}<<\mathrm{f}_{\mathrm{c}}, \mathrm{V}_{2}(\mathrm{f}) \sim \mathrm{f}^{1}$ and $\mathrm{V}_{3}(\mathrm{f}) \sim \mathrm{f}^{1}$, while as $\mathrm{f}>>\mathrm{f}_{\mathrm{c}}, \mathrm{V}_{2}(\mathrm{f}) \sim \mathrm{f}^{-1}$ and $\mathrm{V}_{3}(\mathrm{f}) \sim \mathrm{f}^{-2}$. Eqs. (1) $\sim(2)$ can be approximated individually by a piece-wise linear function (Fig. 1).

$\mathrm{E}_{\mathrm{s}}$ is calculated by the following expression:

$$
\mathrm{E}_{\mathrm{s}}=4 \pi \rho \beta \int \mathrm{v}^{2}(\mathrm{t}) \mathrm{dt}=4 \pi \rho \beta\left[2 \int \mathrm{V}^{2}(\mathrm{f}) \mathrm{df}\right],
$$


where $\rho$ and $\beta$ are, respectively, the density and the S-wave velocity. In principle, the first integral is performed from $-\infty$ to $+\infty$ in the time domain and the second one from 0 to $+\infty$ in the frequency domain. Define:

$$
I_{V}=\int v^{2}(t) d t=2 \int V^{2}(f) d f
$$

Thus, $\mathrm{E}_{\mathrm{s}}=4 \pi \rho \beta \mathrm{I}_{\mathrm{V}}$.

\section{THE EFFECT DUE TO FINITE FREQUENCY BANDWIDTH LIMITATION}

Wang (2004) derived the formulas to show the $f f b l$-effect based on the $\omega^{-2}$ model. For the purpose of comparison, his formulas are shown again below. In the following, we add a subscript ' $\mathrm{o}$ ' to denote a quantity obtained through integration from $-\infty$ and $+\infty \mathrm{sec}$ in the time domain or from 0 to $\infty \mathrm{Hz}$ in the frequency domain. Inserting Eqs. (1) and (2) into Eq. (4), respectively, leads to:

$$
\begin{aligned}
& \mathrm{I}_{\mathrm{V} 2 \mathrm{o}}=\mathrm{I}_{\mathrm{V}}\left(\mathrm{f}_{1}=0, \mathrm{f}_{\mathrm{u}}=\infty\right)=\Omega_{o}{ }^{2}\left(2 \pi \mathrm{f}_{\mathrm{c}}\right)^{3} / 4, \\
& \mathrm{I}_{\mathrm{V} 3 \mathrm{o}}=\mathrm{I}_{\mathrm{V}}\left(\mathrm{f}_{1}=0, \mathrm{f}_{\mathrm{u}}=\infty\right)=\Omega_{o}{ }^{2}\left(2 \pi \mathrm{f}_{\mathrm{c}}\right)^{3} / 16,
\end{aligned}
$$

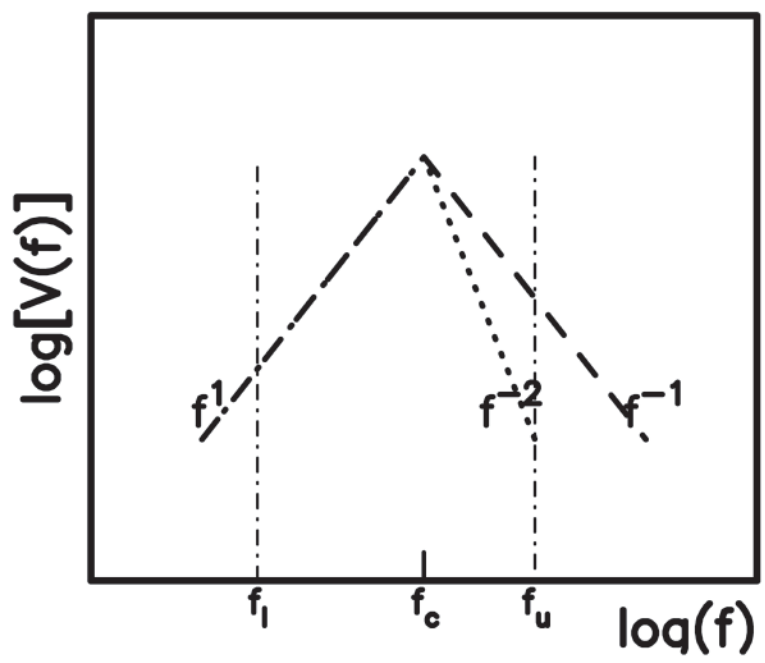

Fig. 1. The log-log plots of the normalized, simplified velocity spectra, V(f) versus frequency, f: the dashed and dotted lines, respectively, for the $f^{-1}$ and $f^{-2}$ source velocity models. The two vertical dashed-dotted lines display the frequency band in use. 
where the subscript is 2 for the $\omega^{-2}$ model and 3 for the $\omega^{-3}$ model. Clearly, $\mathrm{I}_{\mathrm{V} 20}=4 \mathrm{I}_{\mathrm{V} 30}$. When integration is made only in a finite frequency band from $f_{1}$ to $f_{u}$, with $f_{1}<f_{c}<f_{u}$, which is in between two dashed-dotted lines as shown in Fig. 1, the ffbl-effect exists. When $\mathrm{f}_{\mathrm{c}} / \mathrm{f}_{\mathrm{l}}=\mathrm{f}_{\mathrm{u}} / \mathrm{f}_{\mathrm{c}}$, for the $\omega^{-2}$ model the high-frequency cut-off part with $\mathrm{f}>\mathrm{f}_{\mathrm{u}}$ is almost equal to that from the lowfrequency one with $\mathrm{f}<\mathrm{f}_{1}$; while for the $\omega^{-3}$ model the former is smaller than the latter.

Inserting Eqs. (1) and (2) into Eq. (4), with $\mathrm{f}_{\mathrm{l}}<\mathrm{f}_{\mathrm{c}}<\mathrm{f}_{\mathrm{u}}$, respectively, gives:

$$
\begin{aligned}
& \mathrm{I}_{\mathrm{V} 2}=2 \Omega_{\mathrm{o}}{ }^{2} \int(2 \pi \mathrm{f})^{2}\left[1+\left(\mathrm{f} / \mathrm{f}_{\mathrm{c}}\right)^{2}\right]^{-2} \mathrm{df}, \\
& \mathrm{I}_{\mathrm{V} 3}=2 \Omega_{\mathrm{o}}{ }^{2} \int(2 \pi \mathrm{f})^{2}\left[1+\left(\mathrm{f} / \mathrm{f}_{\mathrm{c}}\right)^{2}\right]^{-3} \mathrm{df},
\end{aligned}
$$

where the integral range is of from $f_{1}$ to $f_{u}$. After integration, Eqs. (7) and (8), respectively, becomes:

$$
\begin{aligned}
& \mathrm{I}_{\mathrm{V} 2}=\mathrm{I}_{\mathrm{V} 2 \mathrm{0}} \mathrm{F}_{\mathrm{V} 2}, \\
& \mathrm{I}_{\mathrm{V} 3}=\mathrm{I}_{\mathrm{V} 30} \mathrm{~F}_{\mathrm{V} 3},
\end{aligned}
$$

where

$$
\begin{aligned}
\mathrm{F}_{\mathrm{V} 2}= & (2 / \pi)\left\{-\left(\mathrm{f}_{\mathrm{u}} / \mathrm{f}_{\mathrm{c}}\right) /\left[1+\left(\mathrm{f}_{\mathrm{u}} / \mathrm{f}_{\mathrm{c}}\right)^{2}\right]+\left(\mathrm{f}_{\mathrm{l}} / \mathrm{f}_{\mathrm{c}}\right) /\left[1+\left(\mathrm{f}_{1} / \mathrm{f}_{\mathrm{c}}\right)^{2}\right]+\tan ^{-1}\left(\mathrm{f}_{\mathrm{u}} / \mathrm{f}_{\mathrm{c}}\right)-\tan ^{-1}\left(\mathrm{f}_{1} / \mathrm{f}_{\mathrm{c}}\right)\right\}, \\
\mathrm{F}_{\mathrm{V} 3}= & (4 / \pi)\left\{-\left(\mathrm{f}_{\mathrm{u}} / \mathrm{f}_{\mathrm{c}}\right) /\left[1+\left(\mathrm{f}_{\mathrm{u}} / \mathrm{f}_{\mathrm{c}}\right)^{2}\right]^{2}+\left(\mathrm{f}_{\mathrm{u}} / \mathrm{f}_{\mathrm{c}}\right) / 2\left[1+\left(\mathrm{f}_{\mathrm{u}} / \mathrm{f}_{\mathrm{c}}\right)^{2}\right]+\tan ^{-1}\left(\mathrm{f}_{\mathrm{u}} / \mathrm{f}_{\mathrm{c}}\right) / 2\right. \\
& \left.+\left(\mathrm{f}_{1} / \mathrm{f}_{\mathrm{c}}\right) /\left[1+\left(\mathrm{f}_{1} / \mathrm{f}_{\mathrm{c}}\right)^{2}\right]^{2}-\left(\mathrm{f}_{\mathrm{l}} / \mathrm{f}_{\mathrm{c}}\right) / 2\left[1+\left(\mathrm{f}_{1} / \mathrm{f}_{\mathrm{c}}\right)^{2}\right]-\tan ^{-1}\left(\mathrm{f}_{\mathrm{l}} / \mathrm{f}_{\mathrm{c}}\right) / 2\right\} .
\end{aligned}
$$

When $\mathrm{f}_{1}=0$ and $\mathrm{f}_{\mathrm{u}} \rightarrow \infty, \mathrm{F}_{\mathrm{V} 2}=1$ and $\mathrm{F}_{\mathrm{V} 3}=1$, and, thus, $\mathrm{I}_{\mathrm{V} 2}=\mathrm{I}_{\mathrm{V} 2 \mathrm{o}}$ and $\mathrm{I}_{\mathrm{V} 2}=\mathrm{I}_{\mathrm{V} 30}$.

Hereafter, let $\mathrm{E}_{\mathrm{s}}$ and $\mathrm{E}_{\mathrm{s}}$ ' be the values of seismic radiation energy estimated, respectively, with and without removal of the ffbl-effect. From Eqs. (9) - (12), the energy ratio of $E_{s}$ ' to $E_{s}$ is:

$$
\mathrm{E}_{\mathrm{s} 2}{ }^{\prime} / \mathrm{E}_{\mathrm{s}}=\mathrm{F}_{\mathrm{V} 2}
$$

for the $\omega^{-2}$ model and:

$$
\mathrm{E}_{\mathrm{s} 3}{ }^{\prime} / \mathrm{E}_{\mathrm{s}}=\mathrm{F}_{\mathrm{V} 3}
$$

for the $\omega^{-3}$ model. The variations of $\mathrm{E}_{\mathrm{s} 2}{ }^{\prime} / \mathrm{E}_{\mathrm{s}}$ and $\mathrm{E}_{\mathrm{s} 3}{ }^{\prime} / \mathrm{E}_{\mathrm{s}}$ with $\mathrm{f}_{\mathrm{l}} / \mathrm{f}_{\mathrm{c}}$ are made only for $\mathrm{f}_{\mathrm{l}} / \mathrm{f}_{\mathrm{c}}<1$ and $\mathrm{f}_{\mathrm{l}} / \mathrm{f}_{\mathrm{c}}>1$ under the request of $\mathrm{f}_{1}<\mathrm{f}_{\mathrm{c}}<\mathrm{f}_{\mathrm{u}}$. In other words, the calculations are made when $\mathrm{f}_{1} / \mathrm{f}_{\mathrm{c}}=0.05$ -0.95 and $f_{u} / f_{c}=2$ to 20 , with a difference of 2 . The plots for ten values of $f_{u} / f_{c}$ are shown, respectively, in Fig. 2 (for $\mathrm{E}_{\mathrm{s} 2}{ }^{\prime} / \mathrm{E}_{\mathrm{s}}$ ) and Fig. 3 (for $\mathrm{E}_{\mathrm{s} 3}{ }^{\prime} / \mathrm{E}_{\mathrm{s}}$ ), where the dotted line displays the energy ratio of 1 , without $f f b l$.

In Figs. 2 and 3, all curves are below the dotted line with $\mathrm{E}_{\mathrm{s}}{ }^{\prime} / \mathrm{E}_{\mathrm{s}}=1$, and, thus, $\mathrm{E}_{\mathrm{s} 2}{ }^{\prime} / \mathrm{E}_{\mathrm{s}}$ and $\mathrm{E}_{\mathrm{s} 3}{ }^{\prime} / \mathrm{E}_{\mathrm{s}}$ are both smaller than 1, with a maximum of about 0.937 for $\mathrm{E}_{\mathrm{s} 2}{ }^{\prime} / \mathrm{E}_{\mathrm{s}}$ and 0.999 for $\mathrm{E}_{\mathrm{s} 3}{ }^{\prime} / \mathrm{E}_{\mathrm{s}}$. Obviously, the $f f b l$-effect yields an under-estimation of seismic radiation energy. $\mathrm{E}_{\mathrm{s} 2}{ }^{2} / \mathrm{E}_{\mathrm{s}}$ and 


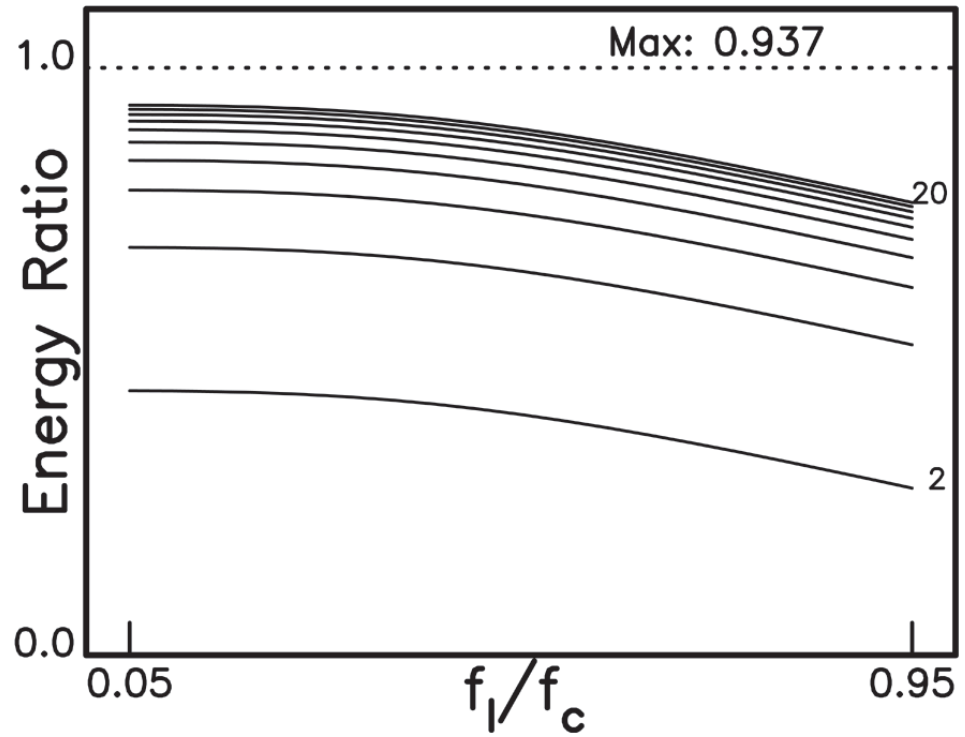

Fig. 2. The variations of $\mathrm{E}_{\mathrm{s} 2}{ }^{2} / \mathrm{E}_{\mathrm{s}}$ with $\mathrm{f}_{\mathrm{l}} / \mathrm{f}_{\mathrm{c}}$ (from 0.05 to 0.95 ) for ten values of $\mathrm{f}_{\mathrm{u}} / \mathrm{f}_{\mathrm{c}}$ (from 2 to 20). The dotted line represents $\mathrm{E}_{\mathrm{s} 2} / \mathrm{E}_{\mathrm{s}}=1$.

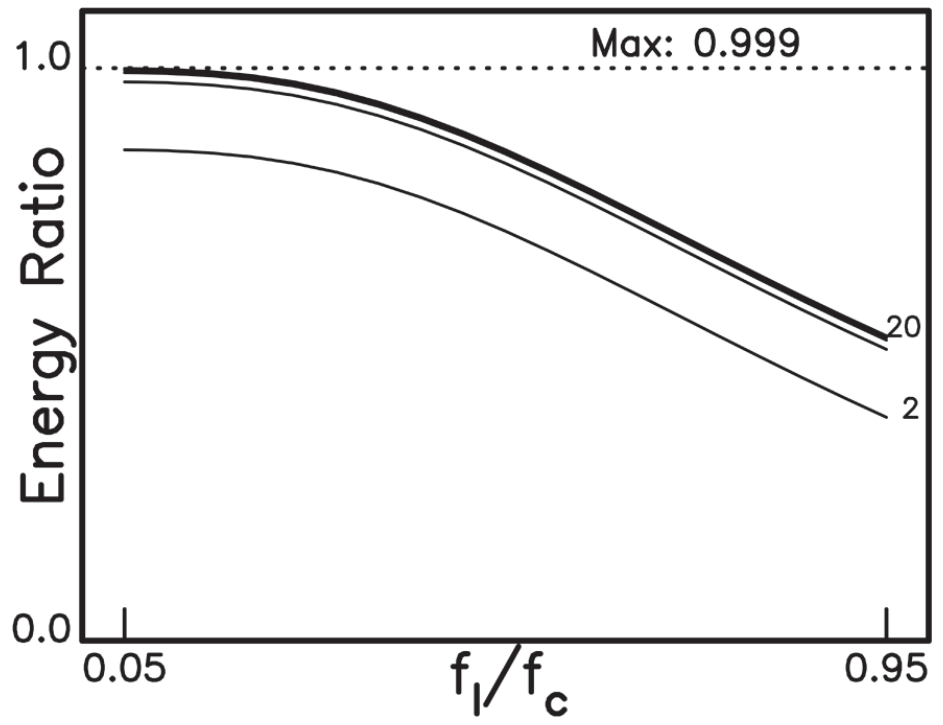

Fig. 3. The variations of $\mathrm{E}_{\mathrm{s} 3}{ }^{\prime} / \mathrm{E}_{\mathrm{s}}$ with $\mathrm{f}_{\mathrm{l}} / \mathrm{f}_{\mathrm{c}}$ (from 0.05 to 0.95 ) for ten values of $\mathrm{f}_{\mathrm{u}} / \mathrm{f}_{\mathrm{c}}$ (from 2 to 20). The dotted line represents $\mathrm{E}_{\mathrm{s} 3}{ }^{\prime} / \mathrm{E}_{\mathrm{s}}=1$. 
$\mathrm{E}_{\mathrm{s} 3}{ }^{\prime} / \mathrm{E}_{\mathrm{s}}$ both decrease with increasing $\mathrm{f}_{\mathrm{l}} / \mathrm{f}_{\mathrm{c}}$, and the amount of the decreasing rate increases with $f_{1} / f_{c}$. For fixed $f_{c}$, decreases in $E_{s 2}{ }^{\prime} / E_{s}$ and $E_{s 3}{ }^{\prime} / E_{s}$ with increasing $f_{1} / f_{c}$ lead to increases in $E_{s 2}{ }^{\prime} / E_{s}$ and $\mathrm{E}_{\mathrm{s} 3} / \mathrm{E}_{\mathrm{s}}$ with decreasing $\mathrm{f}_{1}$. This indicates that an increase in the width of the low-frequency regime improves estimation of $E_{s}$. When $\mathrm{f}_{1} / \mathrm{f}_{\mathrm{c}}<0.4$ for $\mathrm{E}_{\mathrm{s} 2}{ }^{\prime} / \mathrm{E}_{\mathrm{s}}$ and $\mathrm{f}_{\mathrm{l}} / \mathrm{f}_{\mathrm{c}}<0.2$ for $\mathrm{E}_{\mathrm{s} 3}{ }^{\prime} / \mathrm{E}_{\mathrm{s}}$, the curves are almost flat for all $\mathrm{f}_{\mathrm{u}} / \mathrm{f}_{\mathrm{c}}$. This means that $\mathrm{f}_{1}=0.4 \mathrm{f}_{\mathrm{c}}$ for $\mathrm{E}_{\mathrm{s} 2}{ }^{2} / \mathrm{E}_{\mathrm{s}}$ and $\mathrm{f}_{1}=0.2 \mathrm{f}_{\mathrm{c}}$ for $\mathrm{E}_{\mathrm{s} 3}{ }^{\prime} / \mathrm{E}_{\mathrm{s}}$ are the individual optimum lower bounds to lead to a stable value of $\mathrm{E}_{\mathrm{s}}$.

$\mathrm{E}_{\mathrm{s} 2}{ }^{\prime} / \mathrm{E}_{\mathrm{s}}$ and $\mathrm{E}_{\mathrm{s} 3}{ }^{\prime} / \mathrm{E}_{\mathrm{s}}$ both increase with $\mathrm{f}_{\mathrm{u}} / \mathrm{f}_{\mathrm{c}}$. The curves are close to one another for $\mathrm{E}_{\mathrm{s} 2}{ }^{\prime} / \mathrm{E}_{\mathrm{s}}$ when $f_{u} / f_{c} \geqq 10$ and for $E_{s 3}{ }^{\prime} / E_{s}$ when $f_{u} / f_{c} \geqq 4$, thus indicating that $f_{u}=10 f_{c}$ for $E_{s 2}{ }^{\prime} / E_{s}$ and $f_{u}=4 f_{c}$ for $E_{\mathrm{s} 3}{ }^{\prime} / E_{\mathrm{s}}$ are both large enough to lead to a stable estimate of $E_{s}$. For fixed $f_{c}$, increases in $E_{\mathrm{s} 2}{ }^{\prime} /$ $\mathrm{E}_{\mathrm{s}}$ and $\mathrm{E}_{\mathrm{s} 3}{ }^{\prime} / \mathrm{E}_{\mathrm{s}}$ with $\mathrm{f}_{\mathrm{u}} / \mathrm{f}_{\mathrm{c}}$ yield increases in $\mathrm{E}_{\mathrm{s} 2}{ }^{\prime} / \mathrm{E}_{\mathrm{s}}$ and $\mathrm{E}_{\mathrm{s} 3}{ }^{\prime} / \mathrm{E}_{\mathrm{s}}$ with $\mathrm{f}_{\mathrm{u}}$, thus indicating that an increase in the width of high-frequency regime improves estimates of $E_{\mathrm{s}}$. This is consistent with others' (Boore 1988; Di Bona and Rovelli 1988; Singh and Ordaz 1994; Ide and Beroza 2001).

Figures. 2 and 3 show that for fixed $f_{1}$, decreases in $E_{s 2}{ }^{\prime} / E_{s}$ and $E_{s 3}{ }^{\prime} / E_{s}$ with increasing $f_{1} / f_{c}$ lead to increases in $\mathrm{E}_{\mathrm{s} 2}{ }^{\prime} / \mathrm{E}_{\mathrm{s}}$ and $\mathrm{E}_{\mathrm{s} 3}{ }^{\prime} / \mathrm{E}_{\mathrm{s}}$ with $\mathrm{f}_{\mathrm{c}}$, thus implying that the $f f b l$-effect in the lowfrequency regime gives a greater underestimate of $E_{s}$ for events with lower $f_{c}$ than for those with higher $f_{c}$. This effect is stronger for the $\omega^{-3}$ model than the $\omega^{-2}$ model. For fixed $f_{u}$, increases in $\mathrm{E}_{\mathrm{s} 2}{ }^{\prime} / \mathrm{E}_{\mathrm{s}}$ and $\mathrm{E}_{\mathrm{s} 3}{ }^{\prime} / \mathrm{E}_{\mathrm{s}}$ with $\mathrm{f}_{\mathrm{u}} / \mathrm{f}_{\mathrm{c}}$ result in increases in $\mathrm{E}_{\mathrm{s} 2}{ }^{\prime} / \mathrm{E}_{\mathrm{s}}$ and $\mathrm{E}_{\mathrm{s} 3}{ }^{\prime} / \mathrm{E}_{\mathrm{s}}$ with decreasing $\mathrm{f}_{\mathrm{c}}$, thus showing that the $f f b l$-effect in the high-frequency regime yields a bigger underestimate of $E_{s}$ for events with higher $f_{c}$ than for those with lower $f_{c}$. When both $f_{1}$ and $f_{u}$ are finite and fixed, an increase in $\mathrm{f}_{\mathrm{c}}$ will lead to a decrease in both $\mathrm{f}_{\mathrm{l}} / \mathrm{f}_{\mathrm{c}}$ and $\mathrm{f}_{\mathrm{u}} / \mathrm{f}_{\mathrm{c}}$. Hence, the variation of $\mathrm{E}_{\mathrm{s} 2}{ }^{\prime} / \mathrm{E}_{\mathrm{s}}$ and $E_{s 3}{ }^{\prime} / E_{s}$ with $f_{c}$ can be either of the following two types: (1) the ratio first slightly increases and then decreases with increasing $f_{c}$; and (2) the ratio monotonously decrease with increasing $f_{c}$.

\section{RE-EVALUATION OF E $\mathrm{S}_{\mathrm{S}}$ OF THE 1999 CHI-CHI EARTHQUAKE}

The $\mathrm{M}_{\mathrm{s}}$ 7.6 Chi-Chi earthquake, which ruptured the Chelungpu fault, struck central Taiwan on 20 September 1999. The epicenter and the fault trace are displayed in Fig. 4. The values of $\mathrm{f}_{\mathrm{c}}$ and $\Omega_{\mathrm{o}}$ at four near-fault stations evaluated by Hwang et al. (2001) are $\mathrm{f}_{\mathrm{c}}=0.064-0.193 \mathrm{~Hz}$ and $\Omega_{\mathrm{o}}=89.4-2350.0 \mathrm{~cm}$. The values of $\mathrm{f}_{\mathrm{c}}$ and $\Omega_{\mathrm{o}}$ are shown in columns 2 and 3 of Table 1 . They also estimated the values of $\mathrm{E}_{\mathrm{s}}$, which is equivalent to $\mathrm{E}_{\mathrm{s} 2}$ ' for the $\omega^{-2}$ model and $\mathrm{E}_{\mathrm{s} 3}$ ' for the $\omega^{-3}$ source model in this study and denoted by $\mathrm{E}_{\mathrm{s}}{ }^{\prime}$ in column 8 of Table 1, at four near-fault seismic stations (see Fig. 4) based on two sets of $f_{1}$ and $f_{u}$ : (1) $f_{1}=0.03$ and $f_{u}=1.0 \mathrm{~Hz}$ at TCU102 and TCU052; and (2) $\mathrm{f}_{1}=0.03$ and $\mathrm{f}_{\mathrm{u}}=3.0 \mathrm{~Hz}$ at TCU076 and TCU129. The values of $f_{l}$ and $f_{u}$ used are shown in columns 4 and 5 of Table 1. In order to obtain a reliable value of $E_{s}$, they eliminated the effects caused by seismic radiation patterns, seismic-wave attenuation, surface amplification, site effect, and instrumental response. Wang (2004) re-evaluated the values of $\mathrm{E}_{\mathrm{s}}$ estimated by Hwang et al. (2001) through the removal of the ffbl-effect based on the $\omega^{-2}$ model. His values of $\mathrm{E}_{\mathrm{s} 2}{ }^{\prime} / \mathrm{E}_{\mathrm{s}}$ and Es are shown in parentheses of columns 9 and 10 in Table 1.

From the values of $f_{c}, f_{l}$, and $f_{u}$ at the four stations, the ratios of $f_{l} / f_{c}$ and $f_{u} / f_{c}$ are calculated and given in column 6 and 7 of Table 1 : $f_{1} / f_{c}$ of from 0.155 to 0.469 and $f_{u} / f_{c}$ of from 8.197 to 




Fig. 4. A map showing the epicenter (in a solid star) of the 1999 Chi-Chi earthquake, the Chelungpu fault (in a solid line), and four nearfault seismic stations (in solid triangles).

Table 1. The values of several parameters at four near-fault seismic stations. In columns 9 and $10, \mathrm{E}_{\mathrm{s}}{ }^{\prime} / \mathrm{E}_{\mathrm{s}}$ and $\mathrm{E}_{\mathrm{s}}$, respectively, includes $\mathrm{E}_{\mathrm{s} 2}{ }^{\prime} / \mathrm{E}_{\mathrm{s}}$ and $\mathrm{E}_{\mathrm{s}}$ for the $\omega^{-2}$ model and $\mathrm{E}_{\mathrm{s} 3}{ }^{\prime} / \mathrm{E}_{\mathrm{s}}$ and $\mathrm{E}_{\mathrm{s}}$ for the $\omega^{-3}$ model. The values of $\mathrm{E}_{\mathrm{s}}{ }^{\prime} / \mathrm{E}_{\mathrm{s}}$ and $\mathrm{E}_{\mathrm{s}}$ not inside the parenthesis are, respectively, $\mathrm{E}_{\mathrm{s} 2}{ }^{\prime} / \mathrm{E}_{\mathrm{s}}$ and $\mathrm{E}_{\mathrm{s}}$ taken from Wang (2004). The values of $E_{s}^{\prime} / E_{s}$ and $E_{s}$ inside the parenthesis are, respectively, $\mathrm{E}_{\mathrm{s} 3}{ }^{\prime} / \mathrm{E}_{\mathrm{s}}$ and $\mathrm{E}_{\mathrm{s}}$ of this study.

\begin{tabular}{|c|c|c|c|c|c|c|c|c|c|}
\hline Stations & $\begin{array}{c}\mathbf{f}_{\mathbf{c}} \\
(\mathbf{H z})\end{array}$ & $\begin{array}{c}\Omega_{0} \\
(\mathrm{~cm})\end{array}$ & $\begin{array}{c}\mathbf{f}_{\mathbf{l}} \\
(\mathbf{H z})\end{array}$ & $\begin{array}{c}\mathbf{f}_{\mathbf{u}} \\
(\mathbf{H z})\end{array}$ & $\mathbf{f}_{\mathbf{l}} / \mathbf{f}_{\mathbf{c}}$ & $\mathbf{f}_{\mathbf{u}} / \mathbf{f}_{\mathrm{c}}$ & $\begin{array}{c}\mathrm{E}_{\mathrm{s}}{ }^{\prime} \\
(\mathrm{ergs})\end{array}$ & $\mathbf{E}_{\mathbf{s}}{ }^{\prime} / \mathbf{E}_{\mathbf{s}}$ & $\begin{array}{c}\mathbf{E}_{\mathbf{s}} \\
(\mathrm{erg})\end{array}$ \\
\hline TCU102 & 0.122 & 551.2 & 0.03 & 1.0 & 0.246 & 8.197 & $9.7 \times 10^{22}$ & $\begin{array}{c}0.840 \\
(0.974)\end{array}$ & $\begin{array}{c}1.2 \times 10^{23} \\
\left(9.9 \times 10^{22}\right)\end{array}$ \\
\hline TCU052 & 0.064 & 2350.0 & 0.03 & 1.0 & 0.469 & 15.625 & $2.5 \times 10^{23}$ & $\begin{array}{c}0.884 \\
(0.877)\end{array}$ & $\begin{array}{c}2.8 \times 10^{23} \\
\left(2.9 \times 10^{23}\right)\end{array}$ \\
\hline TCU076 & 0.193 & 89.4 & 0.03 & 3.0 & 0.155 & 15.544 & $1.0 \times 10^{22}$ & 0.917 & $1.1 \times 10^{22}$ \\
\hline TCU129 & 0.160 & 105.0 & 0.03 & 3.0 & 0.188 & 18.750 & $6.7 \times 10^{21}$ & 0.929 & $7.2 \times 10^{21}$ \\
\hline
\end{tabular}


18.750. The values of $\mathrm{E}_{\mathrm{s} 2}{ }^{\prime} / \mathrm{E}_{\mathrm{s}}$ and $\mathrm{E}_{\mathrm{s}}$ re-evaluated by Wang (2004) based on the $\omega^{-3}$ model are shown in the parentheses of columns 9 and 10 in Table 1. Clearly, the ffbl-effect results in an underestimate of $E_{s}$, and the underestimate is higher at two northern stations than at the southern ones. We calculate the values of $E_{\mathrm{s}}{ }^{\prime} / \mathrm{E}_{\mathrm{s}}$ and $\mathrm{E}_{\mathrm{s}}$ at two northern stations using Eqs. (12) and (13) based on the $\omega^{-3}$ model. Results are shown in the parentheses of columns 9 and 10 of Table 1. Obviously, the results are opposite to those evaluated based on the $\omega^{-2}$ model. The difference is bigger at TCU102 and smaller at TCU052. Based on the $\omega^{-3}$ model, the value of $\mathrm{E}_{\mathrm{s}}$ at TCU102 estimated by Hwang et al. (2001) is good enough.

To examine the problem in advance, we plot the variations of energy ratio with $\mathrm{f}_{\mathrm{c}}$ in the range $0.05-0.20 \mathrm{~Hz}$ in Fig. 5 for two sets of $f_{l}$ and $f_{u}:(1) f_{l}=0.03$ and $f_{u}=1.0 \mathrm{~Hz}$ for northern seismic stations; and (2) $f_{1}=0.03$ and $f_{u}=3.0 \mathrm{~Hz}$ for southern ones. The dashed and solid lines represent, respectively, $\mathrm{E}_{\mathrm{s} 2}{ }^{\prime} / \mathrm{E}_{\mathrm{s}}$ and $\mathrm{E}_{\mathrm{s} 3}{ }^{\prime} / \mathrm{E}_{\mathrm{s}}$ for the northern stations; and the dashed-dotted line shows $\mathrm{E}_{\mathrm{s} 2}{ }^{\prime} / \mathrm{E}_{\mathrm{s}}$ for the southern stations. The estimated results are also plotted by an open circle or a cross attached with a station code in Fig. 5.

In Fig. $5, \mathrm{E}_{\mathrm{s} 2}{ }^{\prime} / \mathrm{E}_{\mathrm{s}}$ first increases and then decreases with increasing $\mathrm{f}_{\mathrm{c}}$. Whereas, $\mathrm{E}_{\mathrm{s} 3}{ }^{\prime} / \mathrm{E}_{\mathrm{s}}$ first increases with $f_{c}$ and then becomes flat when $f_{c}>0.14 \mathrm{~Hz}$. The variations are as expected as mentioned above. The three variations are all below the dotted line with $\mathrm{E}_{\mathrm{s}}{ }^{\prime} / \mathrm{E}_{\mathrm{s}}=1$, thus showing underestimate of $\mathrm{E}_{\mathrm{s}}$ at the four seismic stations. The solid line intersects the dashed

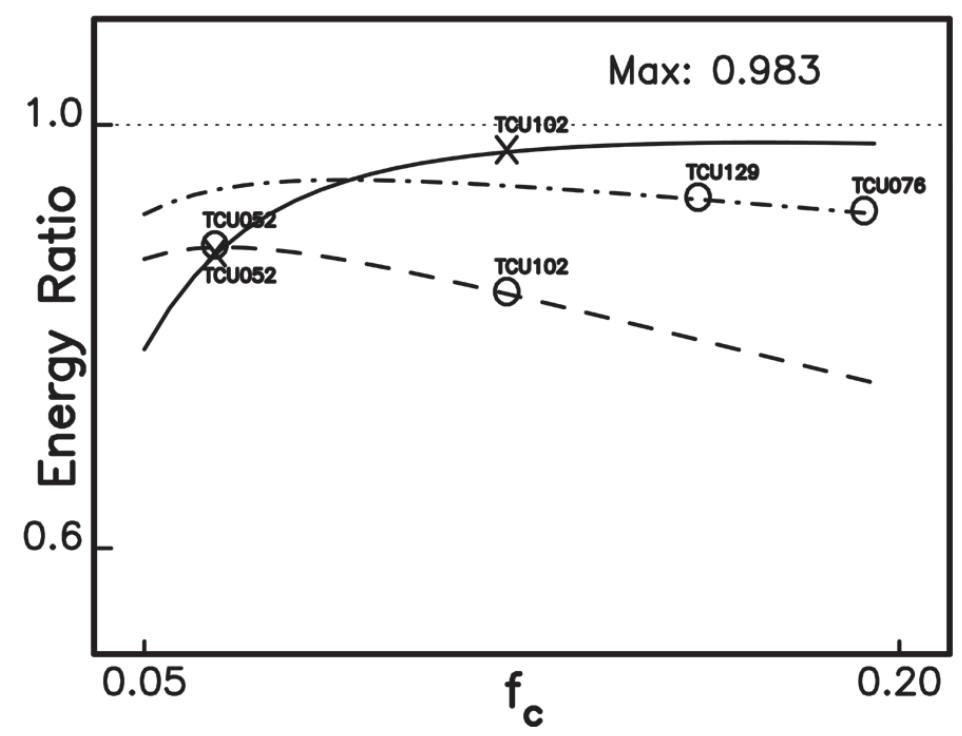

Fig. 5. The variations of energy ratio with $\mathrm{f}_{\mathrm{c}}$ for various values of $\mathrm{f}_{1}$ and $\mathrm{f}_{\mathrm{u}}$ as mentioned in the text: the dashed and solid lines, respectively, for $\mathrm{E}_{\mathrm{s} 2}{ }^{\prime} / \mathrm{E}_{\mathrm{s}}$ and $\mathrm{E}_{\mathrm{s} 3}{ }^{\prime} / \mathrm{E}_{\mathrm{s}}$ at the northern stations, and the dashed-dotted line for $\mathrm{E}_{\mathrm{s} 2}{ }^{\prime} / \mathrm{E}_{\mathrm{s}}$ at the southern ones. The related values at four near-fault seismic stations for the Chi-Chi earthquake are displayed by an open circle or a cross attached with a station code. The dotted line represents $\mathrm{E}_{\mathrm{s}}{ }^{\prime} / \mathrm{E}_{\mathrm{s}}=1$. 
and dashed-dotted ones at $\mathrm{f}_{c}=0.065$ and $\mathrm{f}_{\mathrm{c}}=0.090 \mathrm{~Hz}$, respectively. Hence, at the northern stations the underestimate of $E_{\mathrm{s}}$ is smaller from the $\omega^{-2}$ model than from the $\omega^{-3}$ model when $\mathrm{f}_{\mathrm{c}}<0.065 \mathrm{~Hz}$, and opposite when $\mathrm{f}_{\mathrm{c}}>0.065 \mathrm{~Hz}$. The difference between the effects from the two models is small at TCU052 and large at TCU102. Underestimation of $E_{s}$ is smaller at the southern stations than at the northern ones when $\mathrm{f}_{\mathrm{c}}<0.09 \mathrm{~Hz}$, and opposite when $\mathrm{f}_{\mathrm{c}}>0.09 \mathrm{~Hz}$. Consequently, the values of $\mathrm{E}_{\mathrm{s}}$ at the four near-fields suggested by this study are $9.9 \times 10^{22} \mathrm{erg}$ at TCU102, $2.9 \times 10^{23} \mathrm{erg}$ at TCU052, $1.1 \times 10^{22} \mathrm{erg}$ at TCU076, and $7.2 \times 10^{21} \mathrm{erg}$ at TCU129.

\section{CONCLUSION}

The ffbl-effect of source spectrum on estimation of seismic radiation energy, $\mathrm{E}_{\mathrm{s}}$, is analyzed theoretically on the basis of the $\omega^{-2}$ and $\omega^{-3}$ source models. Such an effect depends on $\mathrm{f}_{\mathrm{l}} / \mathrm{f}_{\mathrm{c}}$ and $\mathrm{f}_{\mathrm{u}} / \mathrm{f}_{\mathrm{c}}$. Numerical results obviously show that $\mathrm{E}_{\mathrm{s}}$ are underestimated for all $\mathrm{f}_{\mathrm{l}} / \mathrm{f}_{\mathrm{c}}$ and $\mathrm{f}_{\mathrm{u}} / \mathrm{f}_{\mathrm{c}}$. An increase in the frequency bandwidth including either the high- or low-frequency regime will increase reliability of estimating $E_{s}$. When $f_{u} / f_{c}<20$, the effect is sensitive to both $f_{l} / f_{c}$ and $\mathrm{f}_{\mathrm{u}} / \mathrm{f}_{\mathrm{c}}$ for the $\omega^{-2}$ model, but mainly to $\mathrm{f}_{\mathrm{l}} / \mathrm{f}_{\mathrm{c}}$ for the $\omega^{-3}$ model. When $\mathrm{f}_{\mathrm{u}} / \mathrm{f}_{\mathrm{c}}>20$, the effect is insensitive to $f_{u} / f_{c}$ for the two models. For the two source models, $E_{s}{ }^{\prime} / E_{s}$ depends on $f_{c}$ in either: (1) $E_{s}{ }^{\prime} / E_{s}$ first slightly increases and then decreases with increasing $f_{c}$; or (2) $E_{s}{ }^{\prime} / E_{s}$ monotonously decreases with increasing $f_{c}$. Numerical results also suggest that Fig. 2 or 3 together with Fig. 5 can help us to select an appropriate frequency band for estimating a reliable value of seismic radiation energy. The values of $f_{l}$ and $f_{u}$ leading to an optimum estimate of $E_{s}$ are $\mathrm{f}_{1}=0.4 \mathrm{f}_{\mathrm{c}}$ and $\mathrm{f}_{\mathrm{u}}=10 \mathrm{f}_{\mathrm{c}}$ for the $\omega^{-2}$ model and $\mathrm{f}_{\mathrm{l}}=0.2 \mathrm{f}_{\mathrm{c}}$ and $\mathrm{f}_{\mathrm{u}}=4 \mathrm{f}_{\mathrm{c}}$ the $\omega^{-3}$ model.

For the $1999 M_{s}$ 7.6 Chi-Chi, Taiwan, earthquake, the revised values of $E_{s}$ show that $E_{s}$ was underestimated by Hwang et al. (2001). However, the degree of underestimates varies from station to station. At the northern stations underestimation of $E_{s}$ is smaller for the $\omega^{-2}$ model than for the $\omega^{-3}$ model when $\mathrm{f}_{\mathrm{c}}<0.065 \mathrm{~Hz}$, and opposite when $\mathrm{f}_{\mathrm{c}}>0.065 \mathrm{~Hz}$. The difference between the effects from the two models is small at TCU052 and large at TCU102. Underestimation of $E_{s}$ is smaller at the southern stations than at the northern ones when $f_{c}<0.09 \mathrm{~Hz}$, and opposite when $f_{c}>0.09 \mathrm{~Hz}$. The values of $E_{s}$ at the four near-field are $9.9 \times 10^{22} \mathrm{erg}$ at TCU102, $2.9 \times 10^{23} \mathrm{erg}$ at TCU052, $1.1 \times 10^{22} \mathrm{erg}$ at TCU076, and $7.2 \times 10^{21} \mathrm{erg}$ at TCU129.

Acknowledgements The authors would like to express their thanks to two reviewers for valuable comments and suggestions. The study was financially supported by Academia Sinica and the National Sciences Council under Grant No. NSC94-2119-M-001-012.

\section{REFERENCES}

Aki, K., 1967: Scaling law of seismic spectrum. J. Geophys. Res., 72, 1217-1231.

Beresnev, I. A., and G. M. Atkinson, 1997: Modeling finite-fault radiation from the $\omega^{-\mathrm{n}}$ spectrum. Bull. Seismol. Soc. Am., 87, 67-84.

Bolt, B. A., 1986: Seismic Energy release over a broad frequency band. Pure Appl. Geophys., 124, 919-930. 
Boore, D. M., 1988: The effect of finite bandwidth on seismic scaling relationships. in Earthquake Source Mechanics. AGU Geophys. Mono., 27, 275-283.

Brune, J. N., 1970: Tectonic stress and the spectra of seismic shear waves from earthquake. $J$. Geophys. Res., 75, 4997-5009.

Di Bona, M., and A. Rovelli, 1988: Effects of the bandwidth limitation on stress drops estimated from integrals of the ground motions. Bull. Seismol. Soc. Am., 78, 1818-1825.

Huang, M. W., and J. H. Wang, 2002: Scaling of displacement spectra of the 1999 Chi-Chi, Taiwan, earthquake from near-fault seismograms. Geophys. Res. Lett., 29, 47/1-4.

Huang, M. W., J. H. Wang, R. D. Hwang, and K. C. Chen, 2002: Estimates of source parameters of two large aftershocks of the 1999 Chi-Chi, Taiwan, earthquake in Chia-Yi area. Terr. Atmos. Ocean. Sci., 13, 299-312.

Hwang, R. D., J. H. Wang, B. S. Huang, K. C. Chen, W. G. Huang, T. M. Chang, H. C. Chiu, and C. C. Tsai, 2001: Estimates of stress drop from near-field seismograms of the $\mathrm{M}_{\mathrm{s}} 7.6$ Chi-Chi, Taiwan, earthquake of September 20, 1999. Bull. Seismol. Soc. Am., 91, 11581166.

Ide, S., and G. C. Beroza, 2001: Does apparent stress vary with earthquake size? Geophys. Res. Lett., 28, 3349-3352.

Singh, S. K., and M. Ordaz, 1994: Seismic energy release in Mexican subduction zone earthquakes. Bull. Seismol. Soc. Am., 84, 1533-1550.

Smith, K. D., J. N. Brune, and K. F. Priestley, 1991: The seismic spectrum, radiated energy, and Savage and Wood inequality for complex earthquakes. Tectonophysics, 188, 303320 .

Wang, J. H., 2004: The seismic efficiency of the 1999 Chi-Chi, Taiwan, earthquake. Geophys. Res. Lett., 31, L10613, doi: 10.1029/204GL019417.

Wang, J. H., 2006: Energy release and heat generation during the 1999 Chi-Chi, Taiwan, earthquake. J. Geophys. Res., 111, B11312, doi: 10.1029/2005JB004018.

Wang, J. H., and M. W. Huang, 2007: Effect of finite frequency bandwidth limitation on evaluations of seismic radiation energy of the 1999 Chi-Chi Earthquake. Terr. Atmos. Ocean. Sci., 18, 567-576, doi: 10.3319/TAO.2007.18.3.567(T). 